\title{
Dime en qué lengua publicas y te diré qué tipo de científico eres. Reflexiones de Pío del Río Hortega sobre la lengua, el patriotismo y las comunicaciones científicas
}

\author{
Pablo von Stecher ${ }^{1}$ \\ Universidad de Buenos Aires, Consejo Nacional de Investigaciones \\ Cientificas y Técnicas, Argentina
}

\begin{abstract}
Resumen
Al menos desde la primera mitad del siglo $\mathrm{XX}$, una disyuntiva interrogó a distintas figuras de la ciencia española e hispanoamericana: si comunicar sus hallazgos en revistas y lenguas extranjeras con el fin de ampliar su difusión, o bien apelar al español y, aún con las limitaciones que ello implicaba, apostar a la trascendencia de sus investigaciones en lengua nacional. En el ensayo "La ciencia y el idioma" (1937), el médico Pío del Río Hortega fundamenta la importancia patriótica de difundir en español y discute con aquellos que optan por hacerlo en idiomas extranjeros, por caso, los médicos e investigadores Santiago Ramón y Cajal y Bernardo Houssay (Premio Nobel en 1906 y 1957, respectivamente). El presente artículo aborda las consideraciones de Río Hortega, analiza sus fundamentaciones y, paralelamente, establece un diálogo con las posturas de Cajal y de Houssay. El trabajo se inscribe en una perspectiva glotopolítica, cuyo
\end{abstract}

\footnotetext{
1 Para correspondencia, dirigirse a: Pablo von Stecher (pablovonstecher@gmail.com), 25 de Mayo 217, $1^{\circ}$ piso, Instituto de Lingüística, Facultad de Filosofía y Letras (Universidad de Buenos Aires). Código Postal: 1002, Ciudad Autónoma de Buenos Aires, Argentina.
} 
propósito es el estudio de las intervenciones en el espacio público del lenguaje (Arnoux y Del Valle 2010), perspectiva operativa para indagar las distintas representaciones sobre el español como lengua de la ciencia. En este enfoque, los textos son analizados como discursos, es decir, en tanto formulados en condiciones históricas de producción, por lo que su indagación implica un estudio simultáneo y recíproco de sus dimensiones verbales y sociohistóricas (Maingueneau 2012). Adelantamos que en la palabra de Río Hortega puede leerse una temprana advertencia sobre el proceso de minorización lingüística del español en la esfera científica, que sus contribuciones terminológicas pueden ser consideradas como una expresión de su posicionamiento, y que las posturas aquí formuladas anticipan interrogantes que actualmente interpelan a aquellos investigadores que producen su labor desde lenguas diferentes o espacios distantes de las grandes potencias científicas.

Palabras clave: lengua, comunicaciones científicas, representaciones, minorización lingüística.

TELL ME IN WHAT LANGUAGE YOU PUBLISH AND I WILL TELL YOU WHAT Kind OF SCIENTIST YOU ARE. Pío DEL Río HoRTEGA's REFLECTIONS ON LANGUAGE, PATRIOTISM AND SCIENTIFIC COMMUNICATIONS

\begin{abstract}
At least since the first half of the $20^{\text {th }}$ century a quandary confronted different figures of Spanish and Hispano-American science: whether to communicate their findings in foreign journals and languages in order to widen their diffusion, or to resort to Spanish and, even with the limitations that that implied, to take a chance on the transcendence of their investigations in the national tongue. In his essay " $\mathrm{La}$ ciencia y el idioma" (1937), the physician Pío del Río Hortega substantiates the patriotic importance of disseminating in Spanish and debates with those that decide to do it in foreign languages, such as the physicians and researchers Santiago Ramón y Cajal and Bernardo Houssay (Nobel Prize in 1906 and 1957 respectively). The present article addresses the considerations of Río Hortega, analyses their foundations and, simultaneously, engages in dialogue with the positions of Cajal and Houssay. This work is grounded in a glotopolitical perspective whose purpose is the study of interventions in the public space of language (Arnoux and Del Valle 2010), an operative perspective to inquire into the different representations of Spanish as the language of science. From this perspective, texts are analysed as discourse, that is to say, as formulated in historical
\end{abstract}


conditions of production, which means that their inquiry implies a simultaneous and reciprocal study of their verbal and sociohistorical dimensions (Mangueneau 2012). We anticipate that in the words of Río Hortega there can be read an early warning on the process of linguistic minorization of Spanish in the scientific sphere, that his terminological contributions can be considered an expression of his positioning, and that the positions here formulated anticipate interrogations that currently question those researchers that carry out their work in different languages or places distant from great scientific powers.

Keywords: language, scientific communications, representations, linguistic minorization.

Recibido: $15 / 09 / 19 \quad$ Aceptado: $18 / 03 / 20$

\section{INTRODUCCIÓN}

Durante la primera mitad del siglo XX, reconocidos investigadores hispanohablantes reflexionaron sobre las dificultades y desafíos implicados en la publicación de artículos científicos en español, así como sobre las limitaciones en el uso de esta lengua en reuniones y congresos internacionales. Entre estos puede destacarse el proyecto ideado por el ingeniero cantábrico Leonardo Torres Quevedo (1852-1936), presentado en el Congreso Científico Internacional Americano realizado en Buenos Aires (1910). Como representante de la delegación española al evento, Torres Quevedo planificó la creación de la Unión Internacional Hispanoamericana de Bibliografía y Tecnología Científicas cuyos principales propósitos serían gestionar la incorporación del español a las lenguas oficiales (alemán, inglés, francés) en jornadas científicas y conformar un Diccionario Tecnológico Hispanoamericano de la Lengua Castellana. Desafortunadamente, por dificultades económicas y administrativas, esta última empresa quedaría trunca y el glosario no llegaría a superar la letra "a", culminando su publicación con el término arquibuteo hacia 1930.

El célebre histólogo y anatomista español Santiago Ramón y Cajal (1852-1934) y el reconocido fisiólogo argentino Bernardo Houssay (18871971) tienen en común no solo el hecho de haber obtenido el Premio Nobel (en 1906 y 1947, respectivamente), sino también el de haber orientado la investigación científica en sus países. Paralelamente a los aportes en sus 
especialidades, su obra escrita comprende una serie de ensayos y conferencias en los que se propusieron guiar a jóvenes y estudiantes en la carrera científicoacadémica. Algunos de estos textos incluyen consideraciones específicas sobre el necesario compromiso patriótico de todo investigador y sobre los desafíos que debe afrontar a la hora de comunicar y difundir los artículos en su propia lengua ${ }^{2}$.

No obstante, ha sido el médico histólogo español Pío del Río Hortega (1882-1945) una de las figuras de la ciencia hispana que mayores reflexiones ha generado al respecto. Discípulo de Cajal en España y luego exiliado en la Argentina, Río Hortega reconoce los hallazgos clíncos y el compromiso patriótico de Cajal y de Houssay. Sin embargo, les cuestiona que hubieran difundido parte de sus producciones en lenguas extranjeras. Con cierta preocupación, advierte la reiteración de esta práctica en otros investigadores y señala los perjuicios que genera sobre la lengua.

En este artículo analizamos las consideraciones y el posicionamiento de Río Hortega referidos al uso del español en actividades de comunicación científica. Para ello, abordamos su ensayo "La ciencia y el idioma" (1937), así como algunas de sus contribuciones al ámbito de la histología y de la neurología patológica: "El tercer elemento de los centros nerviosos, 1920; "La glía de escasas radiaciones (oligodendroglía)", 1921; "Lo que debe entenderse por tercer elemento de los centros nerviosos", 1924. Paralelamente, establecemos un diálogo entre estas reflexiones y los discursos de Cajal y de Houssay, e indagamos los argumentos y contrapuntos que orientan las distintas miradas sobre el fenómeno. Previamente, señalamos los postulados teóricos -glotopolíticos y discursivos- que guían el análisis y presentamos las referencias históricas necesarias para contextualizar, concisamente, acerca del uso y la circulación de las lenguas en las comunicaciones científicas del período abordado y sobre la trayectoria de Río Hortega.

2 Se trata de los volúmenes: Reglas y consejos de la investigación científica. Los tónicos de la voluntad (tercera edición, 1913) y Recuerdos de mi vida. Tomo II: Historia de mi labor cientifica (1917) de Cajal; y de las conferencias y artículos: "El porvenir de las ciencias en la Argentina" (1929), "Discurso en el homenaje que se le tributó al cumplir 25 años de profesor" (1934), "The Tercentenary of Harvard College" (1936a), "Discurso al asumir la presidencia de la Academia Nacional de Medicina" (1936b), "Fines, organización y descripción del Instituto de Fisiología" (1939), "Función social de la Universidad" (1940), "La investigación científica" (1942) y "El presente y el porvenir de la fisiología" (1959) de Houssay; textos que serán referidos en este trabajo. Recordamos que Cajal fue galardonado con el Premio Nobel (1906) a raíz de su investigación sobre la morfología de las neuronas, sus conexiones y la estructura del sistema nervioso. El Nobel de Houssay (1947), en tanto, se debió a su estudio sobre la participación del lóbulo anterior de la hipófisis en el metabolismo de los hidratos de carbono, contribución de interés para el tratamiento de la diabetes. 
Mediante este trabajo pretendemos realizar un aporte a la reflexión sobre el fenómeno de minoración lingüística de la lengua española en el ámbito científico. Entendemos la minorización lingüistica como el proceso a través del cual una lengua (que bien puede pertenecer a una mayoría) resulta subordinada como efecto de un forzamiento paulatino efectuado por los hablantes de otra lengua. Como correlato de la expansión de la lengua dominante, les son impuestas a los hablantes de la lengua minorizada normas de uso social restrictivas en determinados ámbitos (Aracil 1983, Calaforra 2003). Las minorizaciones lingüísticas, procesos que tienen un punto máximo de consolidación cuando los propios hablantes aceptan y se convencen de la poca utilidad de su lengua (Canuto 2017: 86), traen aparejadas tanto limitaciones discursivas, en términos de esquemas argumentales o incluso géneros discursivos que quedan relegados, como limitaciones de carácter léxico y terminológico (Arnoux 2015: 291). En este sentido, y situados en una actualidad en la que el español continúa siendo una lengua minorizada para la actividad científica, el trabajo apuesta a contribuir al conocimiento de las causas que habrían derivado en este fenómeno, a desentramar las distintas posturas al respecto a partir del estudio de las intervenciones producidas y a observar cómo se reactualizan en nuestro presente algunos tópicos y representaciones referidos en la palabra de Río Hortega acerca de la(s) lengua(s) de la ciencia.

\section{REFERENTES TEÓRICOS, ANTECEDENTES Y PUNTOS DE PARTIDA HACIA EL ANÁLISIS}

El trabajo se inscribe en una perspectiva glotopolitica, originariamente definida por los sociolingüistas franceses Louis Guespin y Baptiste Marcellesi (1986) como el estudio de las diversas formas en que una sociedad actúa (de manera más o menos consciente) sobre el lenguaje. Si bien son materiales privilegiados de un estudio glotopolítico los instrumentos lingüísticos (diccionarios, gramáticas, retóricas) y las legislaciones y reglamentaciones de las lenguas, también se constituyen como su objeto de indagación diversos ensayos o artículos que, producidos desde distintos ámbitos (científico, político, periodístico, educativo) reflexionan sobre las prácticas lingüísticas o se proponen intervenir sobre la lengua. Al abordar estos documentos, la glotopolítica indaga las representaciones sociolingüísticas, es decir, aquellas que refieren y evalúan tanto objetos lingüísticos (lenguas, variedades, hablas, acentos, registros, modos de leer o de escribir) como a los sujetos con los 
que tales objetos resultan asociados. Estas representaciones se integran a ideologías lingüísticas, o sea, a los sistemas de ideas que articulan aquellos objetos con formaciones culturales, políticas o sociales específicas. (Arnoux y Del Valle 2010: 5-6, Del Valle 2007: 20) ${ }^{3}$

En el enfoque glotopolítico, concisamente entendido entonces como el estudio de las intervenciones en el espacio público del lenguaje y de las ideologías que activan y sobre las que inciden, los textos son analizados como discursos, es decir, en tanto producidos en condiciones históricas concretas que han dejado su huella en el material textual (Arnoux y Nosthein 2013: 9). De allí que adscribamos, a lo largo del trabajo, a la concepción de discurso adoptada por las tendencias francesas de Análisis del Discurso que lo entienden como la intrincación de un texto y un lugar social, por lo que su análisis supone un estudio simultáneo y recíproco de sus dimensiones verbales y de sus dimensiones históricas y sociales (Maingueneau 2005: 66, 2012: 4). En la misma línea, y en tanto es predominantemente argumentativa la secuencia que orienta la palabra de Río Hortega, abordamos los mecanismos polémico-argumentativos atendiendo a su dimensión institucional y social. (Amossy 2008: 14-16, 2016: 25-26)

Una vez registrados los textos, se efectuó un análisis atento a dos tipos de fenómenos, relativos a la naturaleza genérico-discursiva de los documentos que conforman el corpus. Por un lado, sobre el material ensayístico, se relevaron las representaciones sobre el español como lengua de la comunicación científica y sus vinculaciones con: a) las representaciones acerca del alemán (entre otras "lenguas sabias") en el ámbito hispano y b) las representaciones de los investigadores hispanohablantes que articulan estas lenguas para difundir sus hallazgos. Para ello, se indagaron los ideologemas subyacentes a los enunciados que tematizan esta problemática y el léxico descriptivo que caracteriza a los científicos y su práctica al articular cada lengua ${ }^{5}$. Por otro lado, sobre los estudios en materia de histología nerviosa,

La glotopolítica se nutre del concepto de ideologías lingüisticas proveniente de la antropología norteamericana, caracterizadas como mediadoras entre las estructuras sociales y los usos del lenguaje, representaciones que interpretan la relación entre las formas sociales y las formas del habla. (Kroskrity 2000: 8, Woolard 2012: 23)

4 Ruth Amossy inscribe el estudio de la argumentación en el seno del Análisis del Discurso (específicamente en los enfoques franceses contemporáneos) lo que implica, en términos generales, conferirle al análisis argumentativo su dimensión socioinstitucional antes que concebirlo en el espacio abstracto de la lógica pura. (2008: 14-16)

5 Los ideologemas son las máximas ideológicas que subyacen a un enunciado y en las que se apoyan los razonamientos (Angenot 1982). Dentro del campo glotopolítico, la observación de los ideologemas es una forma de adentrarse en el estudio de los sistemas 
se indagaron los mecanismos enunciativos que refieren a los procesos de creación terminológica en español y los recursos polémico-argumentativos que sustentan la posición teórica de Río Hortega frente a otras posturas. Entendemos que ambas dimensiones del análisis resultan complementarias para abordar de manera comprensiva la postura del autor sobre el problema del español como lengua minorizada en actividades científicas.

Distintas investigaciones se constituyen como antecedentes de interés para el desarrollo de este trabajo. Por un lado, desde la historia de la ciencia se han intentado registrar las circunstancias y motivos que habrían contribuido al relegamiento de la lengua española en el ámbito de la ciencia y de la tecnología. Las consideraciones se inscriben, antes que nada, en la denominada "polémica por la ciencia española", discusión que puede rastrearse entre los problemas culturales que habrían preocupado al pueblo español y que consiste en la reflexión sobre su idoneidad (o no) para la investigación científica y sobre la limitación de sus contribuciones. En esta polémica, en la que intervinieron científicos e intelectuales como Ortega y Gasset, Menéndez Pelayo, Rey Pastor, Unamuno y el mismo Ramón y Cajal, se evaluaron diversas cuestiones, tales como los rasgos que describirían la personalidad de los españoles, en términos de soberbios, perezosos, poco previsores y, con ello, incompatibles con el carácter del investigador, pero también el modo en que los intereses bélicos, religiosos y artísticos (antes que científicos) atravesaron la historia y la idiosincrasia de la península ibérica (Laín Entralgo 1994, Madariaga de la Campa 1994) ${ }^{6}$. Se ha destacado, en resumen, que fue la escasa producción científica formulada por los españoles

lingüístico-ideológicos. Entre otros ideologemas que remiten a la lengua y han dominado en distintas épocas y lugares, pueden mencionarse: "una nación se define por la posesión de una lengua y debe tener su propio Estado", "las sociedades tecnológicamente avanzadas poseen lenguas superiores", "las lenguas son libres e iguales de derechos", "la diversidad lingüística es una riqueza que debe ser defendida". (Arnoux y Del Valle 2010: 12-13)

6 Entre las figuras que participaron en esta polémica, Cajal consideró motivos de distinta índole: político-morales, religiosos, de segregación intelectual, e incluso vinculados con la ubicación geográfica de España y con su situación climática desfavorable, pero concluyó que la causa principal fue el pobre y discontinuo rendimiento nacional en relación con el resto de Europa, motivado por "un atraso y sobre todo, una mezquindad teórica deplorable" (Ramón y Cajal 2017; 157). Ortega y Gasset (1906), en tanto, agregó que mientras en países como Francia y Alemania la dedicación a la ciencia se efectuó de manera sistemática, colectiva y en el largo plazo, en España primó la presencia de hombres de ciencia con producciones puntuales, sin mayores precursores y discípulos, y sin una tradición que los trascendiera. Esta producción reducida, menor no solo que la alemana, inglesa y francesa, sino incluso que la italiana, entendía Cajal, había generado que el español no figurara entre las "lenguas sabias" y fuera mayormente desconocido, por lo que aconsejaba a los científicos españoles "inspirados en un patriotismo quijotesco" que desistieran del hábito de imponer la lengua en congresos 
la que habría redundado en la postergación de la lengua en materia científica (Sánchez Ron 2005, García Delgado, Alonso y Jiménez 2013). Otros trabajos, en tanto, se han ocupado de describir y clasificar las actitudes de renombrados científicos hispanohablantes acerca del uso del español en comunicaciones científicas en posiciones que van desde el menosprecio por la lengua hasta aquellas que han hecho una defensa a ultranza del español, registrando también posturas intermedias. En estas últimas ubican a Cajal y Houssay, así como describen a Río Hortega y lo enlistan entre "los científicos que también alentaron el uso del español". (Acosta Rizo y Cuvi 2005: 143)

Por otro lado, diversos estudios lingüísticos y culturales han abordado las causas históricas que confluyeron en el paso de un modelo plurilingüe en materia científica en el que primaban el alemán, el francés y el inglés en distintas especialidades hasta las décadas de 1930 y 1940, a un modelo vertical caracterizado por la posición hegemónica del idioma británico. Hay consenso entre los lingüistas en que no hay idiomas superiores a otros y que la preponderancia de una lengua en determinada actividad no responde a prioridades intelectuales, léxicas o culturales intrínsecas, sino al modo en que sus hablantes imponen su idioma, en un determinado momento histórico, a través del comercio, la cultura, la política o la fuerza. En el caso del inglés, este momento se inscribe hacia el final de la Segunda Guerra Mundial, a partir de la supremacía política, económica y militar que asumen de manera creciente los Estados Unidos (Crystal 1997: 7-8, Navarro 2001: 36). A ello debe agregarse, entre otras transformaciones ocurridas en el periodo de posguerra, la integración de la ciencia y la tecnología en un mismo sistema. Además de poseer un aparato científico teóricamente sofisticado, EE.UU. contaba con los factores clave para el desarrollo tecnológico: la inversión continua de capital, la formación de equipos especializados y la construcción de laboratorios de investigación (Ortiz 2009: 95-97). Todo este florecimiento redundó en el crecimiento exponencial de artículos publicados en inglés en las distintas áreas científicas. Los estudios cienciométricos, originados en 1978 y orientados a través de distintas variables (citaciones, factores de impacto, estadísticas bibliométricas) se han ocupado de confirmar la consolidación del inglés en el ámbito científico, afianzamiento en el que también operó el aumento mundial de autores no angloparlantes que publican sus trabajos en inglés en revistas internacionales y el de las publicaciones locales o regionales que pasaron a publicarse en esta lengua (Navarro 2001:

internacionales, pues solo provocaban la sorpresa y la deserción de los oyentes. (Ramón y Cajal 2017: 76-77) 
37, García Delgado, Alonso y Jiménez 2013: 489, Di Bitetti y Ferreras 2016: 121, Beigel 2017: 847-848)7. Como consecuencia del fenómeno, se ha reflexionado sobre diversas intervenciones o proyectos de políticas lingüísticas para el empoderamiento del español en distintos espacios del territorio hispanohablante (Hamel 2005, Arnoux 2015, Gutiérrez Rodilla 2019, Lauría 2019, entre otros). Hasta donde sabemos, los materiales mencionados no han sido analizados desde la perspectiva aquí presentada y bajo los objetivos propuestos.

Adelantamos que en la palabra de Río Hortega puede leerse una temprana advertencia sobre el proceso de minorización lingüística del español en la esfera científica que se articula con una posición defensiva cimentada en la vinculación lengua-patria; y que sus aportes médico-terminológicos pueden ser leídos como una expresión de esta postura. Adelantamos también que, paralelamente a la fundamentación de su propuesta, sus enunciados devienen en un discurso polémico que pone en cuestión no solo el patriotismo de Cajal, sino que también involucra sus aportes científicos y terminológicos. Creemos, además, que las posiciones aquí formuladas anticipan algunos interrogantes que actualmente interpelan a aquellos investigadores que producen su labor desde lenguas diferentes o espacios distantes de los centros de producción de conocimientos y deben considerar desde qué medios $\mathrm{y}$, sobre todo, en qué idiomas comunicar sus hallazgos y contribuciones.

\footnotetext{
Hacia el año 2000 , el $82 \%$ de artículos en ciencias sociales y humanidades y el 9095\% de aquéllos en ciencias exactas y naturales se publicaron en inglés (Hamel 2013: 322323). Si bien los datos proporcionados por los catálogos del Institute for Science Information -Sience Citation Index Expanded (SCI-Expanded), Social Sciences Citation Index (SSCI) y Arts and Humanities Citation Index (AHCI)- limitan aún más la presencia del español en exactas y naturales hacia 2005 y 2010, la información resulta controversial pues se trata de indicadores que tienden a desconocer la producción de conocimiento fuera de las potencias científicas tradicionales (Navarro 2001: 41, Ortiz 2009: 99, 171, Beigel 2015: 12). Además de la incidencia de la política cienciométrica en el uso del inglés por parte de investigadores (no angloparlantes) en ciencias exactas y naturales, debe indicarse que la redacción de artículos en una lengua que no es la materna resulta más sencilla en estas áreas por la presencia frecuente de expresiones formulaicas y sintagmas recurrentes, muy diferente de la escritura en ciencias sociales y humanísticas, donde la discursividad verbal es fundamental, la traducción resulta más compleja y las transposiciones de términos de un idioma a otro corren el riesgo de perder su sentido original (Hamel 2013: 354, Arnoux 2015: 302). En la Argentina hay una tendencia por parte de los especialistas en ciencias sociales a continuar publicando en español en circuitos nacionales y regionales, así como sigue habiendo una valoración positiva de la comunicación a través del formato libro y no solo del artículo. (Beigel 2015: 15 17-19)
} 


\section{BREVES APUNTES SOBRE LA TRAYECTORIA DE RÍO HORTEGA}

En 1915, cinco años después de concluir su doctorado sobre las "Causas y anatomía patológica de los tumores de encéfalo", Pío del Río Hortega comenzó a trabajar en el Laboratorio de Investigaciones Biológicas de Madrid, entonces dirigido por Santiago Ramón y Cajal. Bajo su orientación, se introdujo en el ámbito de la histología nerviosa, estudio que lo llevó al descubrimiento de dos tipos de células (la microglía y la oligodendroglía). Tal hallazgo, mediante el cual puso en cuestión consideraciones previas de Cajal, le permitió obtener premios, ascensos y reconocimiento internacional, pero también generó recelos y resquemores que culminarían con su expulsión del laboratorio (Cobos 2012: 4, Aránzazu Díaz-Regañón Labajo 2016: 94). Muchos años después, Río Hortega daría cuenta de su compleja relación con Cajal en el célebre volumen El maestro y yo (1944). Previamente, Cajal le había dedicado párrafos celebratorios por sus aportes pero también algunas críticas en Recuerdos de mi vida. (Ramón y Cajal 1917: 578-580)

La Junta para Ampliación de Estudios e Investigaciones Científicas (JAE) resolvió crear entonces un "Laboratorio de Histología Normal y Patológica" para Río Hortega, espacio donde tendría su primer encuentro con Bernardo Houssay, en el marco de una estancia del argentino en Madrid hacia $1924^{8}$. Por entonces, Houssay era director del Instituto de Fisiología y profesor de esta materia en la Facultad de Medicina de la Universidad de Buenos Aires (UBA), y asumía la codirección de la flamante revista madrileña Archivos de Endocrinología y Nutrición. (Riera Palmero y Río Hortega 2004: 181)

Invitado por la Institución Cultural Española de Buenos Aires, Río Hortega viajó por primera vez a la Argentina en 1925. En el marco de las cátedras de Histología y Anatomía Patológica de la Facultad de Medicina de la UBA, dictó una serie de cursos, conferencias y clases prácticas. En estos años publicó un importante número de artículos sobre la aplicación de sus técnicas al diagnóstico del cáncer cerebral. Asumiría también la dirección del Instituto Nacional del Cáncer y la jefatura del Departamento de Anatomía Patológica del Hospital General de Madrid (Cobos 2012: 5, Aránzazu DíazRegañón Labajo 2016: 97-98). Con el inicio de la Guerra Civil Española

8 La JAE, institución creada en 1907 y presidida por Cajal hasta 1934, tuvo como propósito la promoción de la investigación y la formación científica en España y fue un antecedente del actual Consejo Superior de Investigaciones Científicas (CSIC). 
hacia 1936, Río Hortega recibió ofrecimientos de distintas potencias (Estados Unidos, Rusia, Francia, Inglaterra) para trasladar sus investigaciones, pero los rechazó y se mantuvo firme junto con otros médicos con los que firmó un manifiesto a favor del Gobierno de la República. No obstante, en 1937 debió exiliarse. Primero lo hizo en París y después en Oxford.

A fines de 1939 fue nuevamente invitado a trabajar en Buenos Aires. Luego de un paso corto por el Instituto de Investigaciones del Hospital Santa Lucía, recibió una propuesta para incorporarse en la Cátedra de Histología de la Facultad de Medicina de Montevideo. Sin embargo, una invitación de la Institución Cultural Española en Buenos Aires para organizar un laboratorio de investigaciones histológicas hacia 1941 fijaría su residencia en la Argentina hasta su deceso en $1945^{\circ}$. Desde aquí, Río Hortega emprendió la creación y edición de la revista Archivos de Histología Normal y Patológica (1942) que alcanzaría prestigio internacional (Riera Palmero y Río Hortega 2004: 196, Castellano López y González de Mingo 1995: 266). Paralelamente, dirigiría el Laboratorio de Anatomía Patológica del hospital municipal Pedro Fiorito, junto con Moisés Polak, uno de sus más célebres discípulos.

Debe señalarse que en la elección por la Argentina como espacio donde destinar su exilio, la lengua compartida fue un motivo fundamental. En una carta que Río Hortega le envía a Houssay desde Oxford, describe la situación de encontrarse en un medio científico ejemplar, pero manifiesta su deseo de viajar y permanecer "en algún país de habla española. Quiera Dios que pronto pueda normalizar mi vida junto a los que piensan, hablan y sienten como yo" (citado en Aránzazu Díaz-Regañón Labajo 2016: 197). En efecto, se ha recordado que en sus reiteradas asistencias a las tertulias en el café La Casa de Troya de la porteña Avenida de Mayo, Río Hortega recordaba su patria lejana pero al mismo tiempo sentenciaba "¿Quién nos puede quitar la patria, estemos donde estemos?" (Riera Palmero y Río Hortega 2004: 196-197). En este sentido, es posible acercarse a una concepción de patria que, dadas las circunstancias que debió enfrentar, no se limitaba a las fronteras de su país, sino que respondía a un espacio más amplio en el que confluyeran prácticas lingüísticas y tradiciones culturales comunes. En efecto, recuerda Houssay (1945: 131) en las palabras que le dedica en su

\footnotetext{
9 Fundada en 1915 con el fin fomentar los vínculos científicos y culturales entre España y Argentina, la Institución Cultural (entre otras instituciones y convenios acordados) "permitió el pasaje natural" de intelectuales e investigadores españoles durante la Guerra Civil, tales como José Ortega y Gasset, Julio Rey Pastor, Augusto Pi y Suñer, además de Río Hortega, entre otros. (Ortiz 1988: 249, 260)
} 
funeral, Río Hortega se interesaba por "mostrarnos a cada instante lo mucho español que hay en lo argentino".

Como veremos a continuación, un problema que Río Hortega aborda en el ensayo "La ciencia y el idioma", originalmente publicado en los Cuadernos de la Casa de la Cultura de Valencia, es la distinción entre los científicos que promueven una vocación patriótica y los que carecen de ella. Solo los primeros trabajan con el propósito de otorgar a su patria un puesto relevante entre los pueblos de más ponderado rango intelectual. Este patriotismo, no obstante, no debe traducirse en una renuncia a la paternidad de sus creaciones para otorgárselas a su patria ni en el desdén a la publicidad y al legítimo lucro obtenido. El gran desafío, en todo caso, es alcanzar un justo equilibrio entre los intereses personales y los sentimientos altruistas, armonía muy poco frecuente entre los científicos históricamente consagrados. (Río Hortega 1990: 423, 428)

\section{4. ¿DIFUNDIR LA CIENCIA ESPAÑOLA O DIFUNDIR LA CIENCIA EN ESPAÑOL?}

Río Hortega distingue dos tipos de sentimientos -en muchos casos confundidos e imbricados- que albergan quienes se dedican a las tareas científicas: por un lado, la ambición de salir del gris anonimato de la mediocridad profesional, sensación que se potencia por el deseo de adquirir fama dentro y fuera del ámbito nacional. Por otro, el deseo de enaltecer la patria y hacerla estimable entre las naciones de mayor raigambre científica y cultural, sentimiento noble que, sin embargo, pierde su intensidad con el correr de los años. Una variable clave para detectar cuál de estas intencionalidades orienta al investigador español e hispanoamericano radica en el hecho de observar desde qué soportes y, sobre todo, en qué lengua -nacional o extranjera- publica sus hallazgos. (Río Hortega 1990: 423)

En este ensayo, la obra y carrera de Cajal se conforman como un ejemplo paradigmático para ilustrar el modo en que ambos sentimientos se imbrican. En Reglas y Consejos, Cajal explicaba que al publicar sus aportes en español corría el riesgo o bien de ser ignorado por los sabios extranjeros desconocedores de esta lengua o, peor aún, de que sus ideas fuesen reapropiadas y traducidas por investigadores extranjeros "poco escrupulosos en sus citas" (2017: 145). Por ello, decidió comunicar sus primeros hallazgos en revistas internacionales y solo al alcanzar cierto 
renombre apostó a la creación de publicaciones propias en sus espacios de investigación (la Revista de Histología o la Revista Trimestral Micrográfica), a las que vigorizó con el fruto de sus trabajos.

Según su antiguo discípulo, si bien a Cajal lo impulsaba el deseo de colaboración con la obra científica internacional, también lo motivaba un afán de gloria que se manifestaba en su aspiración por anticiparse a otros investigadores y alcanzar, así pues, la anhelada prioridad en sus descubrimientos. Y, aunque había captado la atención de ciertas figuras de la ciencia internacional como el alemán Albert von Kölliker (en 1893) y el sueco Gustav Retzius (en 1896) que debieron aprender el español para abordar su obra, su principal error fue permitir que su patriotismo se doblegara y resintiera al consentir que se publicaran en francés los trabajos de su instituto (Traveux du laboratoire de recherches biologiques de l'Université de Madrid) hacia el final de su carrera. Para alguien que había logrado que "la ciencia que brotaba a raudales de su talento tuviera en nuestra lengua su más bella forma de expresión" y "que el patriotismo de que se hallaba rebosante se derramara en publicaciones que recogieran sus ideas en idioma español", tal comunicación no puede leerse sino en términos de un "tamaño yerro". (Río Hortega 1990: 425)

Ciertos aspectos del caso de Cajal le permiten a Río Hortega reflexionar sobre una "nueva moda" frecuente entre los jóvenes investigadores españoles que, inspirados en aquel deseo de fama, buscan publicar sus artículos en lenguas extranjeras, principalmente en alemán. En este punto, diversifica y especifica las motivaciones que conducen a los jóvenes a esta práctica: 1) satisfacer la "ambición" de ver su nombre junto al de sabios de renombre y "creerse de su misma talla", manifestación de su "vanidad larvada"; 2) otorgar a sus artículos una "apariencia de bondad" y "elevar su categoría" puesto que se presupone admirable toda obra escrita en alemán; 3) lograr con más facilidad verse citados por otros autores; 4) alcanzar ventajas en los concursos, pues al ser el alemán una lengua poco sabida entre los jurados, la publicación tiende a considerarse necesariamente meritoria; 5) evitar "críticas malintencionadas" de competidores locales desconocedores de la lengua. (Río Hortega 1990: 425-426)

El punteo enfatiza no solo el rasgo superficial de los argumentos que confluyen en esta "nueva moda", sino sobre todo su carácter desacertado al resultar manifestaciones de un interés meramente personal, carácter que se explicita al ver que las motivaciones que lo nutren ("ambición", "vanidad", pero también "impulsos egoístas" y "afanes prematuros de notoriedad" - expresiones que retoma en sus conclusiones-), se oponen a 
las virtudes genuinas del científico ${ }^{10}$. Tales motivaciones son producto de representaciones sobreestimadas (apariencia de bondad y categoría, mérito per se) y estratégicas (referencias frecuentes, menos posibilidad de enfrentar críticas y correcciones) que despliega la articulación de la lengua alemana en publicaciones científico-académicas en el espacio hispano.

Es importante recordar que desde fines del siglo XIX y durante las primeras décadas del siglo XX, momento caracterizado por un proceso dinámico de descubrimientos y avances, el alemán primaba como lengua de prestigio en áreas de las ciencias médicas, exactas y naturales. Formaba parte de un modelo plurilingüe en materia científica que se complementaba -en términos generales- con el francés en áreas del derecho y la ciencia política, y con el inglés en áreas de la economía y la geología, proceso que implicaba el aprendizaje de la lengua correspondiente por parte de los investigadores con el fin de acceder la bibliografía de su especialidad (Hamel 2013: 327, Navarro 2001: 35-36). En efecto, los artículos más prestigiosos en las distintas ramas de la medicina se escribían en alemán y, dada la importancia cuantitativa y cualitativa de los hallazgos obtenidos en el país germánico, sus revistas especializadas en biología y ciencias médicas eran las más consultadas (Navarro 2001: 37, Fernández Santarén, García Barreno y Sánchez Ron 2007: 26). Hamel (2013: 327) señala cómo esta lengua, que tuvo su clímax en 1920, inicia su derrumbe como efecto retardado de la Primera Guerra Mundial y sufre su colapso definitivo con la toma del poder del nazismo en 1933 y la expulsión de su eminente comunidad de científicos judíos.

Entonces, si en la actualidad rige el ideologema de que el inglés es la lengua franca de la ciencia, valoración apoyada en las estadísticas de publicación que mencionábamos y en el número de eventos científicos que señalan su hegemonía (Ortiz 2009: 101, Arnoux 2015: 293-294); no

\footnotetext{
10 En su conferencia sobre "La investigación científica" presentada en distintas universidades latinoamericanas (Facultad de Biología y Ciencias Médicas de la Universidad de Chile, Facultad de Medicina de la Universidad de Río de Janeiro, Universidad Nacional de Cuyo, Universidad Nacional del Litoral) entre 1942 y 1943, Houssay prescribirá las principales virtudes del investigador moderno: vocación, entusiasmo, desinterés, generosidad, tenacidad, imaginación, espíritu crítico, orden y método riguroso; frente a las conductas de los pseudo-investigadores que se caracterizan por "publicar mucho", "firmar numerosas contribuciones superficiales de sus colaboradores" o formular trabajos orientados por "la vanidad o egocentrismo y la adulación" (Houssay 1989: 318-320). En Reglas y Consejos (1913), Cajal registraba como una dificultad del joven investigador la admiración excesiva a los científicos consagrados, y estimulaba, entre otras virtudes, el patriotismo, la originalidad y la perseverancia. No obstante, entre otras diferencias con Rio Hortega, Cajal entendía el "afán de gloria" como una actitud también necesaria en todo científico. (Ramón y Cajal 2017: $33,53,65,69)$
} 
es entonces errado afirmar, que el alemán habría tenido un predominio aproximado al menos en áreas de la medicina, la química y las ciencias naturales durante las primeras décadas del siglo $\mathrm{XX}^{11}$. Sin desconocer las diferencias coyunturales y los modos de difundir la ciencia en ambos momentos, la vinculación se inscribe no solo en su presencia determinante en los medios especializados sino también, siguiendo el planteo de Río Hortega, en las representaciones de prestigio, calidad y difusión asegurada que asocian los artículos con la lengua en que son publicados. Se trata, además, en ambos casos, de representaciones que circulan y se cristalizan entre los distintos miembros de la comunidad científico-académica: investigadores-autores, jurados-evaluadores ${ }^{12}$.

Ahora bien, aunque los enunciados de Río Hortega advierten sobre la hegemonía del alemán, no presuponen su conocimiento totalmente asumido en el mundo hispano. Al contrario, al constituirse como el saber solo de algunos, el hecho de conocerlo y poder utilizarlo se vuelve claramente una ventaja sobre otros (colegas, jurados, evaluadores). Entonces, al enfatizar y vincular los caracteres más superficiales de la práctica con las actitudes más "desleales" en la competencia que supone la carrera científico-académica, lo que se intenta es desmontar la legitimidad que supone el uso del alemán como lengua hegemónica entre los hispanohablantes. Esta sección del ensayo construye, además, una suerte de anti-modelo de científico tomando como

11 Debe advertirse que la expresión "lengua franca" ha sido considerada perniciosa en tanto remite a una falsa neutralidad y presupone un beneficio recíproco entre las lenguas, hechos que ocultan el poder ejercido de una lengua sobre las otras (Phillipson 2008: 263). En efecto, en los procesos de minorización las lenguas dominantes aseguran su legitimidad a través del mecanismo de la naturalización, por lo que la limitación de usos o funciones de la lengua minorizada deja de ser vista como una consecuencia de procesos históricos y se presenta como un efecto inevitable de la naturaleza. (Calaforra 2003: 5)

12 Son numerosos los casos actuales que dan cuenta de estas representaciones sobre el inglés. Gutiérrez Rodilla (2017: 35) señala la creencia extendida en España que eleva la calidad de un artículo mediocre y lo vuelve incuestionable por estar escrito en lengua británica, "mientras que un artículo impecable en cuanto al contenido, pero escrito en español y publicado en una revista española, se convierte en sospechoso, de poco fuste científico". En un trabajo de encuestas destinado a los evaluadores del Consejo Nacional de Investigaciones Científicas y Técnicas (Conicet) en la Argentina, se ha relevado cómo las evaluaciones para ingresar a la Carrera de Investigado Científico (CIC) y para promover a categorías superiores, priorizan la publicación en revistas internacionales (en inglés y con alto factor de impacto) en el área de las ciencias exactas y naturales, lo que desalienta la escritura en español y la consolidación de revistas locales (Beigel 2015: 13). De manera recíproca, cuando el investigador debe elegir sus "cinco producciones más relevantes" para postular su ingreso a CIC, la elección apunta a los artículos publicados en inglés en un $90 \%$ de los postulantes en estas disciplinas. (Beigel 2017: 847-848) 
rasgo determinante el idioma de publicación. De modo recíproco, interpela implícitamente al investigador en formación: ¿Mediante qué recursos avanzar en mi carrera científica? ¿Qué intereses estimulan mi progreso?

El carácter estratégico y superficial de estas motivaciones no oculta, sin embargo, la funesta consecuencia que depara para la ciencia nacional, pues la premura en la publicidad que se obtiene mediante la difusión en revistas y lenguas extranjeras no compensa el daño que se le hace al país al ceder a otras naciones derechos de prioridad sobre la ciencia. En particular, en los casos en que el Estado invirtió en tal formación, sostiene Río Hortega, es fundamental que el rendimiento producido en sus centros de estudio quede para siempre incorporado a su patrimonio científico. Esta consideración le permite refutar el contraargumento de quienes sostienen que el patriotismo se conforma sobre todo al asegurar la circulación de los aportes producidos en el país mediante su comunicación en lengua extranjera. Si bien en este caso el ensayo generaliza la crítica y no puntualiza un nombre, no debe soslayarse su carácter polémico frente a la postura de Cajal, pues en Reglas y Consejos éste se había referido a "quienes inspirándose en un patriotismo estrecho y ruin, se obstinan en escribir exclusivamente en revistas españolas, poco o nada leídas en los países sabios". (Ramón y Cajal 2017: 142) ${ }^{13}$

Si lo que está en discusión es el modo en el que se constituye el patriotismo de un científico nos encontramos entonces frente a dos concepciones contrapuestas. La de Cajal se sostiene en los alcances internacionales que pueden tener la difusión de los saberes efectuados en el espacio nacional, más allá de la lengua en la que sean divulgados. La de Río Hortega, en tanto, se apoya en la articulación de la lengua nacional para comunicarlos, pues en caso contrario, los únicos réditos serían para el autor original y para el país que lo publica, pero no para la patria de procedencia del autor, que culminará por ofrecer "revistas sin interés e indignas de figurar en bibliotecas". (Río Hortega 1990: 426)

13 Entendemos al discurso polémico como aquel que confronta, al menos, dos opiniones y que no solo expone y defiende un punto de vista propio sino también busca asegurar su supremacía frente a las otras posiciones en debate (Amossy 2016: 26). Volvemos sobre la polémica entre Cajal y Río Hortega en la sección número 6. 


\section{LENGUAS Y NACIONALISMO EN LAS COMUNICACIONES CIENTÍFICAS}

En tanto publicar en idiomas poco frecuentados en la investigación implica el riesgo o bien de ser ignorado o de que las producciones originales sean susceptibles de ser reformuladas y/o divulgadas en otras lenguas, el científico prefiere publicar en las denominadas "lenguas sabias" (francés, inglés, alemán). A través de esta construcción entimemática, Río Hortega (1990: 425) parece recuperar algunas líneas de la palabra de Cajal. No obstante, en seguida focaliza en el riesgo de las consecuencias, ahora de orden lingüístico, como efecto de esta práctica: a) el acrecentamiento de la producción científica en otras lenguas $\mathrm{y}$, con ello, de su prestigio en congresos, academias y sociedades; b) la postergación sistemática en estos ámbitos de las lenguas con escaso volumen de bibliografía. De este modo, advierte los puntos que confluyen en el proceso de minorización lingüística del español en el ámbito científico. El carácter determinante de estos corolarios los hace devenir, en un mismo acto enunciativo, en los argumentos para recomendar que las publicaciones se efectúen en español.

Ahora bien, hay una zona en la argumentación de Río Hortega en que se desdibuja el desarrollo lógico de los razonamientos. Por un lado, señala que en tanto hay numerosas revistas alemanas y francesas que incorporan los aportes de múltiples autores de diversos espacios (Austria, Hungría, Holanda, los países eslavos, Bélgica, Rumania, Portugal y la América hispana, además de España), su prestigio no es mero fruto del rendimiento científico de las naciones que las producen. Por otro, recomienda que los hispanohablantes comuniquen en su idioma, siguiendo los ejemplos de Rusia y Japón pero también de "la mayor parte de los países" que pugnan por mantener la producción en su propia lengua. Esta última generalización, además de imprecisa, relativiza el dato anterior: ¿son mayoría los países que publican en sus lenguas o en las de las revistas francesas y alemanas? Al continuar con el segundo lineamiento, Río Hortega extrae una conclusión o, mejor dicho, una resolución al problema planteado: reproducir las prácticas de los científicos rusos y japoneses que acompañan la publicación en sus respectivos idiomas y caracteres con un resumen en francés, inglés o alemán, de modo de hacer accesible a los lectores los elementos fundamentales del artículo, esto es, el hecho nuevo con sus pruebas objetivas y las sugerencias que la investigación ocasiona.

El elemento fundamental para sostener la propuesta es, lógicamente, que los artículos cuenten con ideas sólidas y aportes concretos que inciten a lectores e investigadores a la lectura del trabajo extenso. El escollo -no 
poco frecuente- a esta propuesta surge en los artículos de aquellos autores hispanos que abusan de las referencias bibliográficas y los datos precedentes sobre el tema en vez de explayarse en la observación crítica de los fenómenos registrados y su trascendencia. Pero, una vez zanjado este problema no habría dificultad, pues "toda producción de categoría llega a consentimiento internacional más allá del idioma" (Río Hortega 1990: 426). Casi sobre el final del ensayo, volverá sobre la cuestión de la calidad al relativizar la importancia que tiene el gran número de lectores en español. Aunque dada esta cantidad no habría riesgo de que se pierdan los escritos en nuestra lengua, "los cien millones de españoles e hispanoamericanos debemos aspirar a que nuestra literatura científica nos enorgullezca o, al menos, no nos sonroje". (Río Hortega 1990: 428) ${ }^{14}$

$\mathrm{Al}$ reconocer y valorizar el alcance internacional que desplegaban las revistas alemanas -a diferencia de las españolas, por ejemplo-Río Hortega propone una segunda y alternativa solución al problema planteado: recurrir a ellas luego de su publicación en el idioma original. Y, para evitar un rechazo de los editores frente a una propuesta de re-publicación, sin problematizar demasiado la cuestión, sugiere: "se cambia su título, se modifica ligeramente su texto, se sustituye algún grabado y, con la traducción, parecerá diferente" (Río Hortega 1990: 427). Un ejemplo aproximado a esta propuesta podemos advertirlo en la versión en lengua inglesa de su trabajo titulado "Microglía" que apareció como un capítulo del volumen Cytology and cellular pathology of the nervous system, publicado en Nueva York hacia 1932 y en el que Río Hortega resume los aspectos más importantes de sus publicaciones anteriores.

Es importante notar que la crítica que Río Hortega le imputa a Cajal, la hace extensiva a "muchísimos investigadores hispanoamericanos" cuyo nacionalismo también se ve "doblegado" al no percatarse "de que honrando a su lengua honran a su patria". Varios años antes, en 1925, puntualizaba esta imputación mediante una referencia específica. Afirmaba entonces:

14 La reflexión sobre la calidad, la redacción y la formulación de artículos en español ha sido un problemática recurrente que también puede rastrearse en estas y otras voces del archivo. Cajal, por ejemplo, cuestionaba el uso excesivo de hipérboles y recursos retóricos por parte de los españoles y la falta de razonamientos en sus artículos (2017: 140). De manera aproximada, en ensayos como "La fisiología y la medicina" (1926) y "Problemas y orientaciones de la medicina moderna" (1927), Houssay criticaba el uso excesivo de generalizaciones, esquemas y frases sonoras, representativas de los escritos latinoamericanos (aunque-subraya- principalmente de los argentinos) así como la falta de rigor y exactitud en las experimentaciones. (1989: 57, 117) 
(...) para que la ciencia argentina pueda adquirir toda su plenitud es preciso que publique y divulgue sus obras en español. Toda publicación en francés, italiano, etc., corre el riesgo de que pretenda adjudicársela el país del idioma originario, como ocurre con el gran fisiólogo Houssay, parte de cuya gloria se la adjudican los franceses. (Río Hortega, citado por Buch 2006: 42)

Asimismo, reclamaba que la labor entre españoles y argentinos fuera asociada y colaborativa "haciendo que la producción científica escrita en lengua española sea copiosa y cada vez más rica en hechos positivos" (Río Hortega, citado por Buch 2006: 42). Llegado este punto, entendemos que la lengua es la patria es un ideologema fundamental que subyace a la argumentación de Río Hortega. Bajo el propósito de empoderar la ciencia hispanohablante apela a un imaginario de lengua compartida y, con ello, a aquella concepción amplia de patria que excede los límites políticos de una nación. El anclaje en este ideologema aspira a que el investigador hispanohablante se identifique y se vea interpelado a cooperar con quienes construyen la ciencia en su misma lengua ${ }^{15}$.

Al menos desde 1929 y durante toda la década de 1930, pueden leerse algunas continuidades de interés entre estos postulados y los enunciados de Houssay. En estos años, el argentino se referirá a un proyecto científico cooperativo en el cual "la lengua común" es representada como el elemento unificador, la plataforma compartida para un progreso conjunto. No obstante, la apuesta de Houssay apuntará sobre todo a un proyecto regional, basado en la colaboración de los países hispanoamericanos interesados en el adelanto común, pues el progreso de un país se refleja en el de las naciones hermanas ${ }^{16}$. En su artículo sobre "El problema de las becas de perfeccionamiento" (1939a) recomendará que los becarios argentinos hagan sus pasantías, primero, en países sudamericanos (luego podrán ir a Europa o EE.UU.), pues mediante su vinculación colaborarán "al progreso de la ciencia de habla hispana, a la que la lengua une”. (Houssay 1989: 299)

15 Arnoux ha analizado el modo en que el ideologema la lengua es la patria activa en los hispanoamericanos representaciones asociadas a distintos momentos de su historia y, en tanto condensando ideológico, facilita las identificaciones identitarias al remitir a un amplio imaginario colectivo nacional. (2007: 1-2)

16 Al respecto ver: "El porvenir de las ciencias en la Argentina" (1929) 1989: 282; "Discurso en el homenaje que se le tributó al cumplir 25 años de profesor" (1934) 1989: 566; "Fines, organización y descripción del Instituto de Fisiología" (1939b) 1989: 129; "Función social de la Universidad" (1940) 1989: 242, 244. Solo en puntuales casos, incluye en este proyecto coordinado a España y a Brasil ("Discurso al asumir la presidencia de la Academia Nacional de Medicina", Houssay (1936b) 1989: 571). 
En 1936, un año antes de la publicación del ensayo "La ciencia y el idioma", tendría lugar la intervención de Houssay en el Tercer Centenario de la Universidad de Harvard. En su conferencia, pronunciada en inglés, sostuvo que todos los americanos (del Norte y del Sur) deberían conocer los dos grupos de lenguajes americanos: el inglés y el español o portugués. Asimismo, invitó a los conferencistas a que pronuncien sus futuras disertaciones en la lengua del país sede de los congresos a los que asistan (Houssay 1989: 574). La preponderancia lingüística en estos encuentros dejaría de ser, entonces, de "las lenguas sabias" para que fuera de las lenguas locales.

Tanto Río Hortega como Houssay aclararán pronto que su compromiso implica un distanciamiento del-respectivamente denominado- "nacionalismo excesivo" o "patrioterismo", al que consideran altamente dañino. Ese nacionalismo del que debemos "rehuir" y "detestarle", afirma el español, hace que en algunos países solo se considere buena la ciencia elaborada dentro de su territorio (Río Hortega 1990: 428). Houssay, en tanto, concebía al patrioterismo como la creencia fundamentalista de que eran inmejorables las investigaciones realizadas en el país (1989: 274); así como denunciaba la perniciosa tendencia nacionalista de las grandes potencias de considerar solo los artículos publicados en su territorio o en su idioma y de desestimar con deplorable desatención las formulaciones elaboradas en otros espacios $(1989: 210,219)^{17}$. Ambos, en fin, focalizan en la necesidad de desmontar la vinculación entre la calidad de un artículo y la lengua en que fue producido.

\section{6. "MICROGLÍA"Y OTROS TÉRMINOS PARA DECIR LA CIENCIA EN ESPAÑOL}

Se ha señalado que la versión en inglés sobre el estudio de la "Microglía" ha sido el trabajo de Río Hortega más citado en la literatura mundial (Castellano

17 Houssay presenta esta denuncia en inglés, en el volumen número 18 de la revista estadounidense Annual Review of Physiology (1956), a través del artículo "Trends in Physiology as seenfrom South America" hecho que, sumado a su intervención en Harvard, ilustra su intención de instalar estas consideraciones también en el ámbito angloparlante. Tres años después vuelve sobre el mismo punto, ahora en español, en su discurso de apertura al XXI Congreso Internacional de Ciencias Fisiológicas, titulado "El presente y el porvenir de la Fisiología", celebrado en Buenos Aires (1959). 
López y González de Mingo 1995: 268). También se ha indicado que este hecho atentó contra el deseo de su autor, en tanto fue su texto en otra lengua el que mantuvo vivo su nombre en la ciencia contemporánea (González Quirós 2016: 56). Yendo todavía más lejos, podríamos decir que tampoco pudo evitar que su apellido quedara directamente asociado a su descubrimiento a través de un fenómeno de eponimia ${ }^{18}$, pues en junio de 1925 el diario argentino $\mathrm{La}$ Razón publicaba una nota que daba cuenta cómo en Alemania la microglía era denominada Célula de Hortega. Ya un año antes, los científicos alemanes A. Metz y H. Spatz, luego de confirmar la veracidad de la teoría del español, se referían con frecuencia a la Hortegazellen. (Aránzazu Díaz-Regañón Labajo, 2016: 96)

Por los ya mencionados alcances que despliega la difusión científica en inglés, en particular a partir de la segunda mitad del siglo XX, no es sorpresivo que aquél haya sido su texto más referido. Sabemos, por otra parte, que la vinculación de sus contribuciones con la trascendencia de su nombre escapaba al deseo de Río Hortega, según él mismo lo declara. Tal vez interese rescatar, en cambio, el hecho de que el título de la publicación se resuma a una sola palabra: el neologismo (en español) creado por su autor.

Si una de las funciones fundamentales de las revistas científicas en lengua española es "crear el ámbito terminológico y lingüístico necesario para que la ciencia y todos sus avances puedan transmitirse y pensarse en español" (González Quirós 2016: 57), creemos entonces que la fundamentación de la postura de Río Hortega se sustenta no solo a través de sus argumentos sino también a partir de sus propios aportes terminológicos en las áreas de histología nerviosa.

En una de sus contribuciones fundamentales, Río Hortega indica: "nuestras investigaciones nos demuestran la existencia de dos tipos celulares diferentes". Los primeros, con apéndices ramificados y diseminados sobre todo en la sustancia gris, "constituyen, para nosotros, la microglía". En tanto, las células apolares de la sustancia blanca, agrupadas en columnas, "difieren de la microglía y forman grupo distinto (...) las llamaremos glía interfascicular" (1920: 69). No obstante, un año después, establece un

18 Gallardo observa que aunque son diversos los procedimientos para crear neologismos en el ámbito de la ciencia, el más habitual es el de recurrir a los formantes cultos grecolatinos (raíces, prefijos y sufijos) que se unen por mecanismos de composición y derivación, por ejemplo: "biosfera" o "parenogénesis", entre muchísimos otros. De todos modos, explica que otros se originan a través de nombres propios, lo que se conoce como eponimia, que corresponden al descubridor de un fenómeno, una enfermedad o una parte del cuerpo, como ocurre en "mal de Alzheimer" o "área de Brocca" (2019: 9). 
monitoreo del léxico previamente acuñado con el fin de perfeccionar la designación: "Como la denominación de glía interfascicular (empleada provisoriamente) indica sólo el principal asiento de los elementos que la constituyen, hemos adoptado la de oligodendroglía o glía de escasas raciones que nos parece más ajustada". (Río Hortega 1921: 63-64)

Se recrea de este modo el proceso de construcción conceptual y de reflexión metalingüística que condujo al autor a alcanzar estas denominaciones. Al respecto, se ha indicado el modo en que la labor del médico (particularmente de aquel que investiga) involucra una actividad cognitivo-verbal: la de elaborar conceptos y construir conocimiento a través de la lengua (Ciapuscio 2009: 233). Las actividades reflexivas sobre el lenguaje permiten, a su vez, que el científico devenido en autor profundice los conceptos y efectúe una comprensión más acabada de las problemáticas que aborda.

En una nueva formulación de sus aportes, Río Hortega revisa las experimentaciones previas de Cajal sobre la existencia de un género especial de corpúsculos intersticiales en los centros nerviosos y afirma:

Cajal dio a esa variedad de células el nombre de tercer elemento, definiéndole como un corpúsculo pequeño, adendrítico, quizás de origen mesodérmico y tan extraño a las neuronas como a la glía (...) Mas, investigaciones nuestras, efectuadas con técnica original, persuadiéronnos pronto que dicho tercer elemento estaba realmente integrado por dos células sin parentesco alguno morfológico, histogénico, funcional, a las que describimos con los nombres de microglía y oligendroglía respectivamente. (Río Hortega 1924: 33-34)

En este fragmento, Río Hortega resume el proceso de creación terminológica a partir de una corrección efectuada sobre el trabajo de su antiguo maestro. La enunciación y el conector adversativo escenifican y confrontan dos modos en la construcción de conocimientos. Por un lado, mientras la investigación de Cajal es presentada como una elaboración individual a través de una tercera persona del singular, el nosotros en Río Hortega, que puede detectarse también en los textos anteriormente mencionados, configura (al menos discursivamente) la idea de un trabajo en conjunto ${ }^{19}$. Por otro, el descubrimiento y el neologismo propuestos por Cajal surgen de un proceso que adquiere un carácter impreciso: el adverbio "quizás" modaliza

19 En distintos momentos de El maestro y yo, Río Hortega describe las dificultades que implicaba trabajar en equipo con Cajal así como señala que su escuela, hacia 1920 "no había desarrollado ningún movimiento expansivo y se hallaba enquistada como un capillita, integrada sólo por españoles que eran pocos y mal avenidos". (1986: 126) 
el enunciado en términos de duda y desestabiliza la especificación de un origen conciso del corpúsculo; tampoco sugiere precisión la denominación del fenómeno como "tercer elemento", definido negativamente por su diferencia con las neuronas y las glías. El trabajo de Río Hortega, en cambio, realizado con "técnica original" se construye de modo más exacto y riguroso: el adverbio "realmente" corrobora de manera efectiva que las dos células mencionadas conforman aquel elemento; el adverbio "pronto", en tanto, caracteriza la contundencia persuasiva de los datos obtenidos; la denominación de los elementos, en fin, se construye con mayor exhaustividad a través de los neologismos articulados ${ }^{20}$. En efecto, el matiz correctivo frente al aporte puede notarse desde el título de la contribución: "Lo que debe entenderse por tercer elemento de los centros nerviosos". El título mismo incorpora la denominación fallida y al tiempo en que expone el error de Cajal, tematiza, perfecciona y fundamenta el proceso de conformación de neologismos.

\section{NOTAS FINALES}

La mirada glotopolítica desde la que leímos los discursos de Río Hortega nos permitió detectar los ideologemas subyacentes a sus enunciados. Apreciamos, así pues, el carácter fundamental del ideologema la lengua es la patria en su definición del compromiso (del) científico y en las respectivas recomendaciones de publicación. Como contraparte, resulta notorio el cuestionamiento a las representaciones (compartidas entre los españoles) sobre la hegemonía del alemán como lengua de la medicina y, con ello, el intento por restringir su uso en la escritura científica. Desde estos lineamientos, Río Hortegano solo advierte la minorización del español en la ciencia sino que busca cuestionarlo e intenta revertir el proceso.

Asimismo, diferenciamos las actitudes en torno al español en las obras de las figuras abordadas - sin dudas determinadas por las coyunturas en las que se manifestaron-, lo que permite relativizar miradas homegeneizantes

20 En su clásico estudio sobre la subjetividad en el lenguaje, Kerbrat-Orecchioni incorpora la observación de los adverbios como modalizadores del enunciado. Casos como "quizás" y "realmente" implican un "juicio de verdad" o un "juicio sobre la realidad" y pueden marcar distintos grados de adherencia del sujeto con respecto al contenido del enunciado. (1986: 153-154) 
al respecto, pues si los gestos de Houssay por la defensa del uso del español en congresos y revistas resultan más determinados y contundentes que los de Cajal, la intervención de Río Hortega supone una reflexión más exhaustiva e integral del fenómeno y una posición más comprometida frente a esta problemática. Tampoco se puede evaluar de manera uniforme el compromiso patriótico de Cajal y de Río Hortega, ya que al reconstruir el diálogo entre ambos observamos cómo la opción por una lengua muestra dos concepciones distintas. Y si a Río Hortega le cabría la calificación formulada por Cajal de ser representante de un "patriotismo estrecho y ruin" por publicar mayormente en revistas hispanas, éste será ejemplo de un "patriotismo doblegado" o "resentido" por hacer lo contrario. El caso de Houssay difiere de los anteriores en tanto no fija una posición definitiva al respecto. A lo largo de su obra pueden verse distintas intervenciones que, con el fin de robustecer un proyecto científico primordialmente regional, reivindican la lengua como elemento de filiación y cuestionan las posturas nacionalistas de las grandes potencias; y si bien sus aportes fueron difundidos en revistas de habla hispana, paralelamente también lo hizo en lenguas y publicaciones extranjeras, especialmente en francés.

En tanto, el acotado estudio discursivo sobre el material científico de Río Hortega, además de mostrar cómo se construye enunciativamente la confrontación teórica con Cajal, expone el interés que adquiere el trabajo de creación léxica y reflexión metalingüística en la producción científica. $\mathrm{Si}$ el ensayo denuncia las restricciones que padece la lengua en el ámbito científico, la trascendencia de los aportes médicos de Río Hortega dejan expuesta la importancia de la instauración terminológica para el desarrollo del español en esta actividad, en expresiones que han circulado y circulan, incluso, por otras lenguas.

Poco más de 80 años pasaron desde el escrito de Río Hortega y la reflexión sobre la lengua en la que comunicar los avances y descubrimientos continúa interpelando a los investigadores no angloparlantes. Desde entonces, las nuevas tecnologías potenciaron y diversificaron los medios de difusión científica, las instituciones científico-académicas redefinieron y consolidaron sus criterios de evaluación y, aunque se dejó atrás el modelo plurilingüe para afianzar uno hegemónicamente monolingüe (en áreas de exactas y naturales), ciertas representaciones sobre el prestigio del alemán como lengua de la ciencia parecen reactualizarse en algunas reflexiones actuales sobre el estatuto del inglés. Un caso paradigmático de esta continuidad puede leerse en un muy reciente editorial del Acta de Bioquímica Clínica Latinoamericana, cuyo título es, casualmente, "La ciencia y el idioma". Allí, Horacio Lopardo (2019: 159), Doctor en Bioquímica y director de la revista, califica al factor de impacto como un índice caprichoso destinado a 
mantener la hegemonía del inglés, e invita a los evaluadores e instituciones científicas a buscar formas más creativas de valorar los artículos que eviten la vinculación directa entre la calidad de aportes, la lengua y/ o el medio de su difusión.

Lejos de conformarse como una elección espontánea, definir en qué lengua comunicar las investigaciones se presenta en muchos casos como el resultado conflictivo de distintas tensiones, entre las convicciones del investigador y las exigencias de la evaluación institucional o de los criterios cienciométricos, entre el destinatario al que (mínimamente) se pretende alcanzar y la promesa de su potenciación infinita. Nos preguntamos entonces ¿hasta qué punto son hoy por hoy compatibles los fundamentos de una suerte de lealtad lingüística con los mandatos que rigen el sistema científico? ¿Se pueden generar estrategias para conciliar ambas instancias? ¿Podrán ser, acaso, las ediciones bilingües de muchas revistas nacionales y regionales cuyos artículos se presentan en español o portugués y en inglés una propuesta acertada al respecto?

Pero más allá del investigador puntual y más allá del artículo puntual, se trata de una decisión que acarrea consecuencias para las lenguas, problemática que puede escapar si no al interés tal vez a la percepción del investigador en la mayoría de las áreas. En el último Congreso de la Lengua celebrado en Córdoba (Argentina 2019), en la sección "La comunicación del pensamiento científico en español", el biólogo y divulgador científico Diego Golombek se preguntaba si efectivamente tenía sentido cuestionar o preguntarse por el estatuto del inglés como lengua franca de las ciencias (naturales) y sostenía que, en definitiva, no se trata de idiomas, sino de comunicar bien las investigaciones. Posturas como estas, recurrentes por cierto, nos interrogan: ¿debería ser el interés por la minorización de la lengua una preocupación del científico? ¿No sería, al menos, deseable que se conocieran con más nitidez los distintos y contundentes efectos (lingüísticos, epistemológicos, culturales, políticos) que supone la comunicación masiva en inglés?

\section{REFERENCIAS BIBLIOGRÁFICAS}

Acosta Rizo, Carlos y Nicolás Cuvi. 2005. El español en los intercambios de ciencia y tecnología durante el siglo XX. Panacea. Revista de Medicina, Lenguaje y Traducción 6 (20): 142-147 [en línea]. Disponible en http://www.medtrad.org/panacea/IndiceGeneral/ n20_tribuna_cuvi-acosta.pdf. [Consulta 16/02/2018]. 
Amossy, Ruth. 2008. Argumentation et Analyse du discours: perspectives théoriques et découpages disciplinaires. Argumentation \& Analyse du discours 1: 1-18 [en línea]. Diponible en http://journals.openedition.org/aad/1343 [Consulta 18/02/2018].

2016. Por una retórica del dissensus: las funciones de la polémica. En Ana Montero (comp.). El análisis del discurso polémico, pp. 25-38. Buenos Aires: Prometeo.

Angenot, Marc. 1982. La parole pamphlétaire. París: Payot.

Aracil, Lluís. 1983. Dir la realitat. Barcelona: Edicions dels Països Catalans.

ArÁnZaZu Díaz-Regañón Labajo, María. 2016. El exilio científico republicano en Argentina. Contribuciones e impacto de los médicos, biomédicos y psicoanalistas españoles en la ciencia argentina (1936-2003). Salamanca: Ediciones Universidad de Salamanca.

Arnoux, Elvira. 2007. "La lengua es la patria", "nuestra lengua es mestiza" y "el español es americano": desplazamientos significativos en el III Congreso de la Lengua Española, Miradas sobre la lengua [en línea]. Disponible en https://miradassobrelalengua.blogia. com/2007/091701-elvira-narvaja-de-arnoux-la-lengua-es-la-patria-nuestra-lengua-esmestiza-.php [Consulta 20/05/2019].

2015. Minorización lingüística y diversidad: en torno al español y al portugués como lenguas científicas. Anais do Seminário Ibero-americano de Diversidade Lingüística, pp. 290-306. Brasilia: Iphan.

- y José Del Valle. 2010. Las representaciones ideológicas del lenguaje. Discurso glotopolítico y panhispanismo. Spanish in Context 7 (1): 1-24 [en línea]. Disponible en https://academicworks.cuny.edu/cgi/viewcontent.cgi?article $=1073 \&$ context $=$ gc_pubs [Consulta 20/11/2018].

y Susana Nosthein. 2013. Temas de glotopolitica: Integración regional sudamericana y panhispanismo. Buenos Aires: Biblos.

Beigel, Fernanda. 2015. Culturas evaluativas alteradas. Revista de Política Universitaria 2: $12-21$.

2017. Científicos periféricos, entre Ariel y Calibán. Saberes institucionales y circuitos de consagración en Argentina: las publicaciones de los investigadores del Conicet. DADOS - Revista de Ciências Sociais 60 (3): 825-865 [en línea]. Disponible en https:// ri.conicet.gov.ar/handle/11336/41290 [Consulta 01/08/2019].

Buch, Alfonso. 2006. Ciencia, nación y voluntad. Algunos elementos comparados en el pensamiento de Bernardo Houssay y Santiago Ramón y Cajal. Redes 12 (23): 15-47.

Calaforra, Guillem. 2003. Lengua y poder en situaciones de minorización lingüística. Cracovia: Universidad Jagellónica [en línea]. Disponible en http://www.valencia.edu/ calaforr/CursColonia.pdf [Consulta 01/08/2019].

Canuto, Felipe. 2017. Mantenimiento de una lengua minorizada: el caso del purépecha en Ichány en Tacuro, Michoacán (México). Onomázein 38: 77-96 [en línea]. Disponible en https:/dialnet.unirioja.es/servlet/articulo?codigo $=6476569$ [Consulta 01/08/2019].

Castellano López, Berta y Bernardo González de Mingo. 1995. Contribuciones científicas de Don Pío del Río Hortega a la neurociencia. Neurología 10 (7): 265-276.

Ciapuscio, Guiomar. 2009. Lenguaje y medicina: actividades metalingüísticas en artículos de opinión de mitad del siglo XX. En Eva Eckkrammer (ed.). La comparación en los lenguajes de especialidad, Forum für Fachsprachen-Forschung, pp. 231-241. Berlín: Frank \& Timme.

Cobos, Miriam. 2012. Pío del Río Hortega. El capítulo argentino (Biografía del sabio español), Revista de Historia de la Medicina y Epistemología Médica IV (2): 1-9.

CRYstal, DAvid. 1997. English as a Global Language. Cambridge: Cambridge University Press.

Del Río Hortega, Pío. 1920. El tercer elemento de los centros nerviosos. I. La microglía en estado normal. Boletín de la Sociedad Española de Biología 8: 68-82. 
1921. La glía de escasas radiaciones (oligodendroglía). Boletín de la Real Sociedad Española de Historia Natural 21: 63-92.

1924. Lo que debe entenderse por tercer elemento de los centros nerviosos. Boletín de la Sociedad Española de Biología 11: 33-35.

(1937) 1990. La ciencia y el idioma. En José López Piñeiro (ed.). Pío Del Río Hortega, pp. 421-429. Madrid: Fundación Banco Exterior.

(1944) 1986. El maestro y yo. Madrid: CSIC.

Del Valle, José. 2007. Glotopolítica, ideología y discurso: categorías para el estudio del estatus simbólico del español. En José del Valle (ed.). La lengua ¿patria común? Ideas e ideologías del español, pp. 13-29. Madrid: Iberoamericana.

Di Bitetti, Mario y Julián Ferreras. 2016. Publish (in English) or perish the effect on citation rate of using languages other than English in scientific publications. Ambio 46: 121-127 [en línea]. Disponible en https://www.ncbi.nlm.nih.gov/pubmed/27686730 [Consulta 01/08/2019].

Fernández Santarén, Juan, Pedro García Barreno y José Sánchez Ron. 2007. Santiago Ramón y Cajal un siglo después del Premio Nobel. Santander: Fundación Botín.

Gallardo, Susana. 2019. Términos técnicos y falsos amigos. Ciencia e Investigación 69 (1): 7-13.

García Delgado, José, José Alonso y Juan Carlos Jiménez. 2013. El español, lengua de la comunicación científica. Madrid: Ariel, Fundación Telefónica.

GolombeK, Diego. 2019. La comunicación del pensamiento científico en español. Ponencia presentada en el VIII Congreso Internacional de la Lengua Española "América y el futuro del español. Cultura y educación, tecnología y emprendimiento". Buenos Aires, Argentina [en línea]. Disponible en https://www.youtube.com/watch?v=CQ9iOSbPaCQ [Consulta 10/07/2019].

GonzÁLEz Quirós, José. 2016. Sobre la lengua de la medicina. Educación Médica 19 (1): 56-59 [en línea]. Disponible en https://www.elsevier.es/es-revista-educacion-medica-71-avancesobre-lengua-medicina-S1575181316301528 [Consulta 15/08/2019].

Guespin, Louis y Jean Marcellesi. 1986. Pour la Glottopolitique. Langage 83: 5-34.

Gutiérrez Rodilla, Bertha. 2017. El futuro del español como lengua de la medicina. Educación Médica 18(2): 34-37 [en línea]. https://www.elsevier.es/es-revista-educacionmedica-71-articulo-el-futuro-del-espanol-como-X1575181317608325 [Consulta $15 / 08 / 2019]$.

2019. "Salvar el miembro" y "salvar la función": los dos objetivos primordiales de las publicaciones científicas (médicas) en español. Ponencia presentada en el I Encuentro "La lengua española y las ciencias. Diálogos hispano-mexicanos". Madrid, España.

Hamel, Rainer. 2005. El español en el campo de las ciencias: propuestas para una política del lenguaje. En Congreso Internacional sobre Lenguas Neolatinas en la Comunicación Especializada, pp. 87-112. México: Centro de Estudios Lingüísticos y Literarios.

2013. El campo de las ciencias y la educación superior entre el monopolio del inglés y el plurilingüismo: elementos para una política del lenguaje en América Latina, Trabalhos em Linguística Aplicada 52 (2): 321-384 [en línea]. Disponible en http://www. scielo.br/scielo.php?pid=S0103-18132013000200008\&script=sci_abstract\&tlng=es [Consulta 20/11/2018].

Houssay, Bernardo. (1926) 1989. La fisiología y la medicina. En Ariel Barrios Medina y Alejandro Paladini (eds.). Escritos y discursos del Dr. Bernardo Alberto Houssay, pp. 110-120. Buenos Aires: Eudeba.

(1927) 1989. Problemas y orientaciones de la medicina moderna. En Ariel Barrios Medina y Alejandro Paladini (eds.). Escritos y discursos del Dr. Bernardo Alberto Houssay, pp. 44-59. Buenos Aires: Eudeba. 
(1929) 1989. El porvenir de las ciencias en Argentina. En Ariel Barrios Medina y Alejandro Paladini (eds.). Escritos y discursos del Dr. Bernardo Alberto Houssay, pp. 271-283. Buenos Aires: Eudeba.

(1934) 1989. Discurso en el homenaje que se le tributó al cumplir 25 años de profesor. En Ariel Barrios Medina y Alejandro Paladini (eds.). Escritos y discursos del Dr. Bernardo Alberto Houssay, pp. 559-568. Buenos Aires: Eudeba.

(1936a) 1989. The Tercentenary of Harvard College. En Ariel Barrios Medina y Alejandro Paladini (eds.). Escritos y discursos del Dr. Bernardo Alberto Houssay, pp. 574-575. Buenos Aires: Eudeba.

(1936b) 1989. Discurso al asumir la presidencia de la Academia Nacional de Medicina. En Ariel Barrios Medina y Alejandro Paladini (eds.). Escritos y discursos del Dr. Bernardo Alberto Houssay, pp. 569-573. Buenos Aires: Eudeba.

(1939a) 1989. El problema de las becas de perfeccionamiento. En Ariel Barrios Medina y Alejandro Paladini (eds.). Escritos y discursos del Dr. Bernardo Alberto Houssay, pp. 288-300. Buenos Aires: Eudeba.

(1939b) 1989. Fines, organización y descripción del Instituto de Fisiología. En Ariel Barrios Medina y Alejandro Paladini (eds.). Escritos y discursos del Dr. Bernardo Alberto Houssay, pp. 121-153. Buenos Aires: Eudeba.

(1940) 1989. Función social de la Universidad. En Ariel Barrios Medina y Alejandro Paladini (eds.). Escritos y discursos del Dr. Bernardo Alberto Houssay, pp. 234-244. Buenos Aires: Eudeba.

(1942) 1989. La investigación científica. En Ariel Barrios Medina y Alejandro Paladini (eds.). Escritos y discursos del Dr. Bernardo Alberto Houssay, pp. 302-322. Buenos Aires: Eudeba.

(1945). Doctor Pío del Río Hortega, Archivos de la Universidad de Buenos Aires (Boletín Informativo de la Revista de la Universidad) 20 (1): 130-131.

(1956) 1989. Trends in Physiology as seen from South America. En Ariel Barrios Medina y Alejandro Paladini (eds.). Escritos y discursos del Dr. Bernardo Alberto Houssay, pp. 199-211. Buenos Aires: Eudeba.

(1959) 1989. El presente y el porvenir de la Fisiología. En Ariel Barrios Medina y Alejandro Paladini (eds.). Escritos y discursos del Dr. Bernardo Alberto Houssay, pp. 212-220. Buenos Aires: Eudeba.

Kerbrat-Orecchioni, Catherine. 1986. La enunciación. De la subjetividad en el lenguaje. Buenos Aires: Hachette.

Kroskrity Paul. 2000. Regimenting languages: language ideological perspectives. En Paul Kroskrity (ed.). Regimes of language: ideologies, polities \& identities, pp. 1-34. Oxford: James Currey.

Laín Entralgo, Pedro. 1994. La ciencia española en la época de Torres Quevedo. En Francisco González Redondo (ed.). Acta del Primer Simposio Leonardo Torres Quevedo: su vida, su obra, su tiempo, pp. 17-26. Madrid: Amigos de la Cultura Científica.

LAURÍA, DANIELA. 2019. Intervenciones institucionales y discursos oficiales sobre la lengua en la Argentina kirchnerista (2003-2015): medios de comunicación, ciencia, educación superior y turismo idiomático. En Elvira Arnoux y Roberto Bein (eds.). Ideologías Lingüísticas. Legislación, Universidad, Medios, pp. 17-62. Buenos Aires: Biblos.

Lopardo, Horacio. 2019. La ciencia y el idioma. Acta Bioquímica Clínica Latinoamericana 53 (2): 159-160.

Madariaga de la CAmPa, Benito. 1994. Menéndez Pelayo y Torres Quevedo ante el problema de la ciencia española. En Francisco González Redondo (ed.). Acta del Primer Simposio Leonardo Torres Quevedo: su vida, su obra, su tiempo, pp. 81-91. Madrid: Amigos de la Cultura Científica. 
Maingueneau, Dominique. 2005. L'analyse du discours et ses frontieres, Marges linguistiques 9: 64-75 [en línea]. Disponible en http://dominique.maingueneau.pagesperso-orange.fr/ pdf/L-analyse-du-discours-et-ses-frontieres.pdf [Consulta 20/01/2019].

2012. Que cherchent les analystes du discours? Argumentation \& Analyse du discours 9: 1-12 [en línea]. Disponible en https://journals.openedition.org/aad/1354n [Consulta: 20/03/2019].

Navarro, Fernando. 2001. El inglés, idioma internacional de la medicina.Panace@ Revista de Medicina, Lenguaje y Traducción 2 (3): 35-52 [en línea]. Disponible en https://www. tremedica.org/wp-content/uploads/n3_Panacea3_Marzo2001.pdf [Consulta 15/08/2019].

Ortega y Gasset, José. 1906. La ciencia romántica, El imparcial, edición del 4 de junio de 1906.

Ortiz, EduARDo. 1988. Una alianza por la ciencia: las relaciones científicas entre Argentina y España a principios de este siglo, Llull 11: 247-261.

2009. La supremacía del inglés en las ciencias sociales. Buenos Aires: Siglo XXI.

Phillipson, Robert. 2008. Lingua franca or lingua frankensteinia? English in European integration and globalisation. World Englishes 27 (2): 250-268.

Ramón y Cajal, Santiago. 1917. Recuerdos de mi vida. Tomo II: Historia de mi labor científica. Madrid: Imprenta y Librería de Nicolás Moya.

(1913) 2017. Reglas y consejos de la investigación cientifica. Los tónicos de la voluntad. Madrid: Consejo Superior de Investigaciones Científicas.

Riera Palmero, Juan y Juan del Río Hortega. 2004. Pío del Río Hortega y la institucionalización de la ciencia en España. Actas VIII Congreso de la Sociedad Española de Historia de las Ciencias y de las Técnicas, pp. 161-199. Cádiz.

SÁnchez Ron, José. 2005. El español y la ciencia en lengua española. Panacea. Revista de Medicina, Lenguaje y Traducción 4 (21-22): 201-203. [en línea] Disponible en http:// www.medtrad.org/panacea/IndiceGeneral/n_21-22_editorial.pdf [Consulta: 16/02/2018].

Woolard, Kathryn. 2012. Las ideologías lingüísticas como campo de investigación. En Bambi Scheffelin, Kathryn Woolard y Paul Kroskrity (eds.). Ideologías Lingüisticas. Práctica y Teoria, pp. 19-70. Madrid: Catarata.

S/A. 1925. "Intercambio científico hispano-argentino. El distinguido histólogo español doctor Pío del Río Hortega, nuestro huésped". La Razón, 3 de junio de 1925, p. 115. Buenos Aires. 